\title{
Probability and conspiratorial thinking
}

\author{
Kovic, Marko ; Füchslin, Tobias
}

\begin{abstract}
Conspiracy theories as alternative explanations for events and states of affairs enjoy widespread popularity. We test one possible explanation for why people are prone to conspiratorial thinking: We hypothesize that conspiratorial thinking as an explanation for events increases as the probability of those events decreases. In order to test this hypothesis, we have conducted five experiments in which participants were exposed to different information about probabilities of fictional events. The results of all experiments support the hypothesis: The lower the probability of an event, the stronger participants embrace conspiratorial explanations. Conspiratorial thinking, we conclude, potentially represents a cognitive heuristic: A coping mechanism for uncertainty.
\end{abstract}

DOI: https://doi.org/10.1002/acp.3408

Posted at the Zurich Open Repository and Archive, University of Zurich ZORA URL: https://doi.org/10.5167/uzh-158973

Journal Article

Accepted Version

Originally published at:

Kovic, Marko; Füchslin, Tobias (2018). Probability and conspiratorial thinking. Applied Cognitive Psychology, 32(3):390-400.

DOI: https://doi.org/10.1002/acp.3408 


\title{
Peer-reviewed Publication DOI: https://doi.org/10.1002/acp.3408
}

\section{Probability and conspiratorial thinking}

\author{
Marko Kovic $^{* 1,2}$ and Tobias Füchslin ${ }^{\dagger 1,3}$ \\ ${ }^{1}$ Swiss Skeptics - Association for Critical Thinking, Zurich, Switzerland. \\ ${ }^{2}$ Zurich Institute of Public Affairs Research, Zurich, Switzerland. \\ ${ }^{3}$ Department of Communication and Media Research, University of Zurich, \\ Switzerland.
}

\begin{abstract}
Conspiracy theories as alternative explanations for events and states of affairs enjoy widespread popularity. We test one possible explanation for why people are prone to conspiratorial thinking: We hypothesize that conspiratorial thinking as an explanation for events increases as the probability of those events decreases. In order to test this hypothesis, we have conducted five experiments in which participants were exposed to different information about probabilities of fictional events. The results of all experiments support the hypothesis: The lower the probability of an event, the stronger participants embrace conspiratorial explanations. Conspiratorial thinking, we conclude, potentially represents a cognitive heuristic: A coping mechanism for uncertainty.
\end{abstract}

\section{Introduction: Conspiratorial beliefs and er- rors in probabilistic thinking}

A conspiracy theory is a particular kind of alternative explanation for some event or some state of affairs in the world. Conspiracy theories posit that the "common explanation" for an event or state of affairs is false, and that, in

*marko.kovic@skeptiker.ch / marko.kovic@zipar.org / +41 763350617

${ }^{\dagger}$ t.fuechslin@ipmz.uzh.ch / tobias.fuechslin@skeptiker.ch 
reality, individuals or organizations have caused the event or state of affairs for nefarious reasons (Clarke, 2002; Keeley, 1999). From a purely epistemological point of view, conspiracy theories represent beliefs that are not justified very well, or not at all. This means that the epistemic shortcoming of conspiratorial beliefs is not contingent on their truth status: Even though the propositional content of conspiracy theories can be accidentally true, the way the belief in conspiracy theories is justified is defective. In that sense, conspiracy theories' "crippled" (Sunstein \& Vermeule, 2009) epistemology represents a case of the Gettier problem (Gettier, 1963), or, more generally, a case of epistemic luck (Pritchard, 2004).

Given the epistemic shortcoming of conspiracy theories, the prevalence of conspiratorial thinking is somewhat surprising: Rather than being a fringe occurrence, belief in conspiracy theories is fairly common (Oliver \& Wood, 2014a, 2014b), and, furthermore, belief in conspiracy theories can affect real-world behavior and decision-making (Jolley \& Douglas, 2014b, 2014a; K. Douglas, Sutton, Jolley, \& Wood, 2015). The fact that conspiracy theories are an everyday phenomenon means that accounts of conspiratorial thinking as pathologies (Barron, Morgan, Towell, Altemeyer, \& Swami, 2014; Bentall, Kinderman, \& Kaney, 1994; Darwin, Neave, \& Holmes, 2011) or consequences of maladaptive traits (Swami, Weis, Lay, Barron, \& Furnham, 2016) probably offer only a partial explanation. While it is possible that a subset of conspiratorial reasoning is caused by pathologies of the mind and anomalous personality traits, it is highly improbable that every conspiratorial belief can be explained in this manner. A different and complementary perspective on conspiratorial reasoning is not one of anomaly, but of normalcy: Conspiratorial reasoning as a consequence of general and universal cognitive limitations (Boudry \& Braeckman, 2012). From this point of view, cognitive patterns in the context of conspiracy theories, such as the need for cognitive closure and explanatory completeness (Marchlewska, Cichocka, \& Kossowska, 2017; Leman \& Cinnirella, 2013; Basham, 2001), the need for making sense of high-impact events (Leman \& Cinnirella, 2007; van Prooijen \& van Dijk, 2014), and the need for clear agency (K. M. Douglas, Sutton, Callan, Dawtry, \& Harvey, 2016), are not pathologies, but rather forms of cognitive heuristics, or cognitive biases. 


\subsection{Hypotheses}

Cognitive biases are systematic errors in human cognition that often arise in situations in which we need to subjectively assess probabilities, either explicitly or implicitly (Tversky \& Kahneman, 1974). It has been suggested that conspiratorial thinking is a coping mechanism for uncertainty (Franks, Bangerter, \& Bauer, 2013), but, even though there is some evidence that conspiratorial thinking is linked to errors in probabilistic thinking (Brotherton \& French, 2014; Dagnall, Denovan, Drinkwater, Parker, \& Clough, 2017), the specific hypothesis of conspiratorial thinking as a heuristic for coping with uncertainty has not yet been put to the empirical test. We fill this gap with five experiments that test the following hypothesis: The lower the probability of an event, the stronger the belief in a conspiratorial explanation of the event, and the weaker the belief in the common explanation of the event.

In addition to our main hypothesis, we include two potential mediating factors in our experiments. As mentioned in the previous section, there is some evidence that conspiratorial reasoning might be more prominent when the events in question are of higher impact for society (Leman \& Cinnirella, 2007; van Prooijen \& van Dijk, 2014). We include this mediating factor in our study and hypothesize that belief in a conspiratorial explanation is stronger in a high-impact scenario than in a low-impact scenario. We define a low-impact event as an event that does not affect society as a whole, but only a very small group of people.

A second potentially mediating factor is the clarity of a motive for conspirators to conspire. A prominent feature of conspiracy theories and conspiratorial arguments is intentionality, or the presence of an ulterior, yet clear motive (Uscinski \& Parent, 2014, 43). We include the presence of a clear ulterior motive as a potential mediating factor in our study and hypothesize that belief in a conspiratorial explanation is stronger in a scenario with a clear ulterior motive.

\section{Design, data, methods}

\section{$2.1 \quad$ Five experiments}

We test one main and two auxiliary hypotheses, as described in the previous section. In order to do so adequately, we conducted five separate experiments. The first of those experiments was designed to simply test the impact of event 
probabilities. Experiments two and three test the impact of event probabilities, and in addition, they are low-impact events either without a clear ulterior motive (experiment two) or with a clear ulterior motive (experiment three). Experiments four and five test the impact of event probabilities, and in addition, they are high-impact events either without a clear ulterior motive (experiment four) or with a clear ulterior motive (experiment five)

\subsection{Recruitment of participants}

Participants for the experiments presented in this paper were recruited on the crowdsourcing platform Clickworker (Lutz, 2015). Each participant was remunerated with $€ 0.15$ for completing a short survey that was the experiment. All five experiments were designed to take around one minute to complete. The experiments were conducted with version 2.63.1 of the open-source survey software LimeSurvey (LimeSurvey Project Team / Carsten Schmitz, 2012).

For experiment one (two experimental groups), we commissioned 250 surveys, and for experiments two to five (five experimental groups), 500 surveys per experiment. Our goal was to have, on average, 100 participants per experimental condition. For experiment one, we over-recruited experiment participants, because it was not entirely clear whether only completed surveys were considered part of the commissioned quota, or whether incomplete surveys also counted towards it. When it became obvious during experiment one that only completed surveys counted towards the commissioned quota, we decided not to over-recruit for experiments two and three. The numbers of completed surveys slightly diverge from the commissioned numbers. For experiment one, 244 instead of 250 surveys were completed; for experiment two, exactly 500; for experiment three, 504; for experiment four, 502; and for experiment five, 504. The crowdsourcing platform that we worked with thus has some imprecision in terms of commissioned vs. completed surveys, but the differences are within a $\pm 2.5 \%$ range.

\subsection{Design of experiment one: The lottery}

We have conducted five experiments in order to test the impact of probabilistic information on conspiratorial reasoning. For experiment one, 244 participants ( $65 \%$ women, mean age $=34.8, \mathrm{SD}=11.9)$ were randomly assigned to two groups: 121 participants were assigned to the first group, and 123 participants were assigned to the second group. The participants in the first group were 
exposed to the following text:

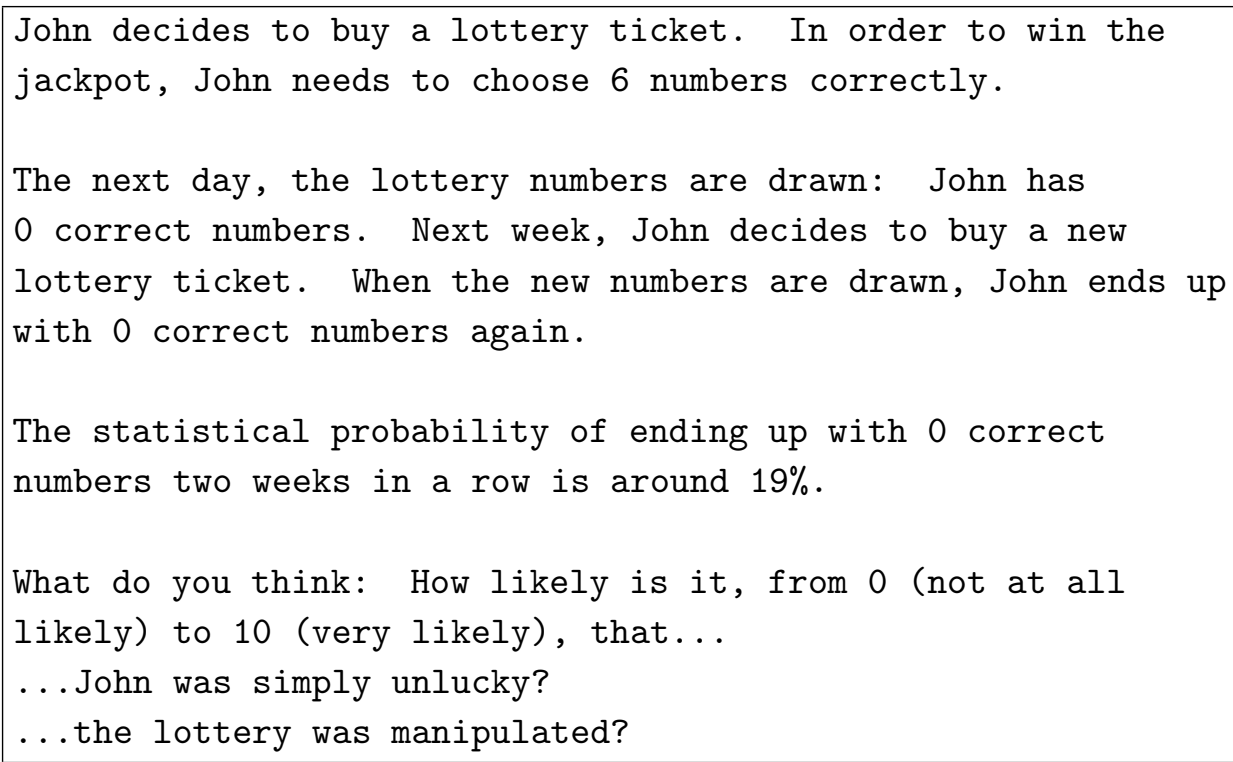

The order of the two questions at the end was randomized. The participants in the second group were exposed to the following text:

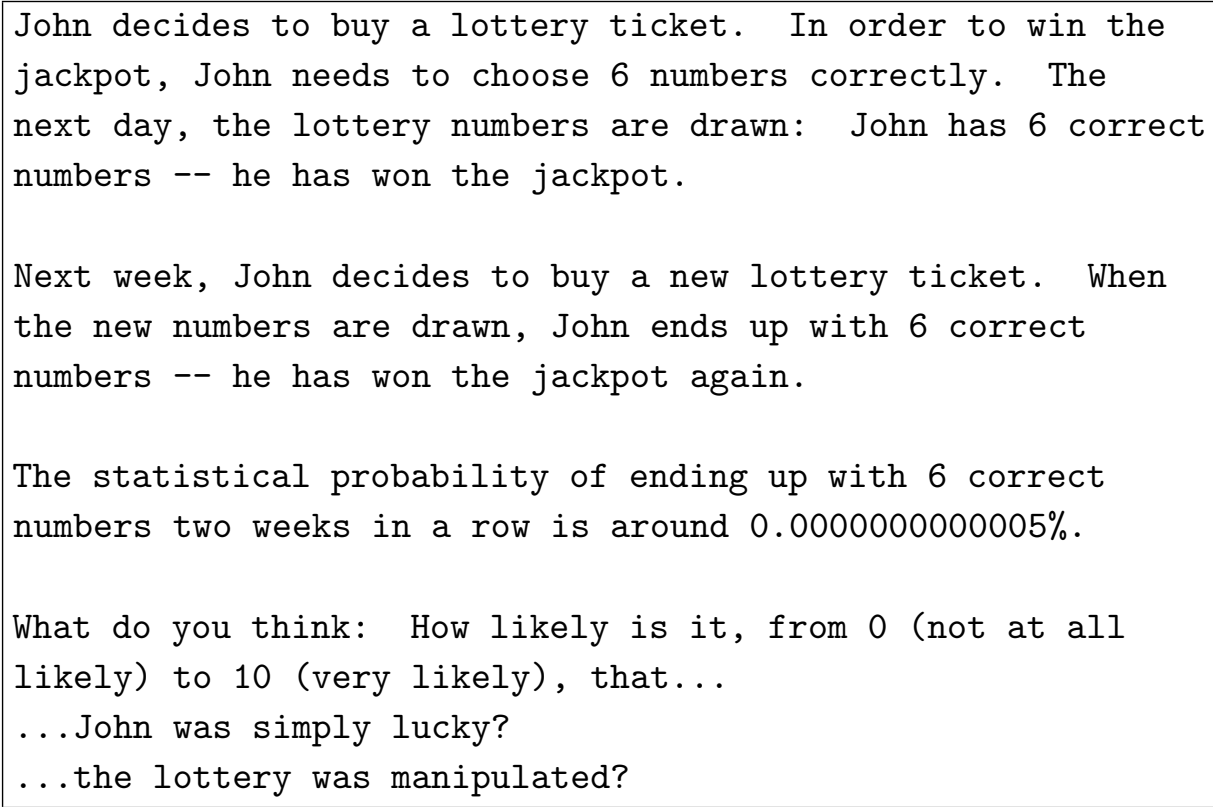


As in the first group, the order of the two questions at the end was randomized. After answering the questions about how likey they though it was that John was (un-)lucky and how likely they though it was that the lottery was manipulated, participants in both groups were asked to provide information on their gender, their age, and their country of residence. For the sake of simplicity, the gender options were female and male only. The probabilities of $19 \%$ in experiment one and $0.0000000000005 \%$ in experiment two are derived from a simple lottery setup with 49 numbers in total.

\subsection{Design of experiment two: Falling roof tile (low impact, lack of clear ulterior motive)}

For experiment two, 500 participants $(64 \%$ women, mean age $=34.2, \mathrm{SD}=$ 12.1) were randomly assigned to five groups: 82 participants were assigned to the first group, 105 to the second group, 101 to the third group, 108 to the fourth group, and 104 to the fifth group. The participants in all groups were exposed to a nearly identical text. The only difference, marked here as $\mathrm{XX} \%$, was the probabilistic information that each group received about the event in question:

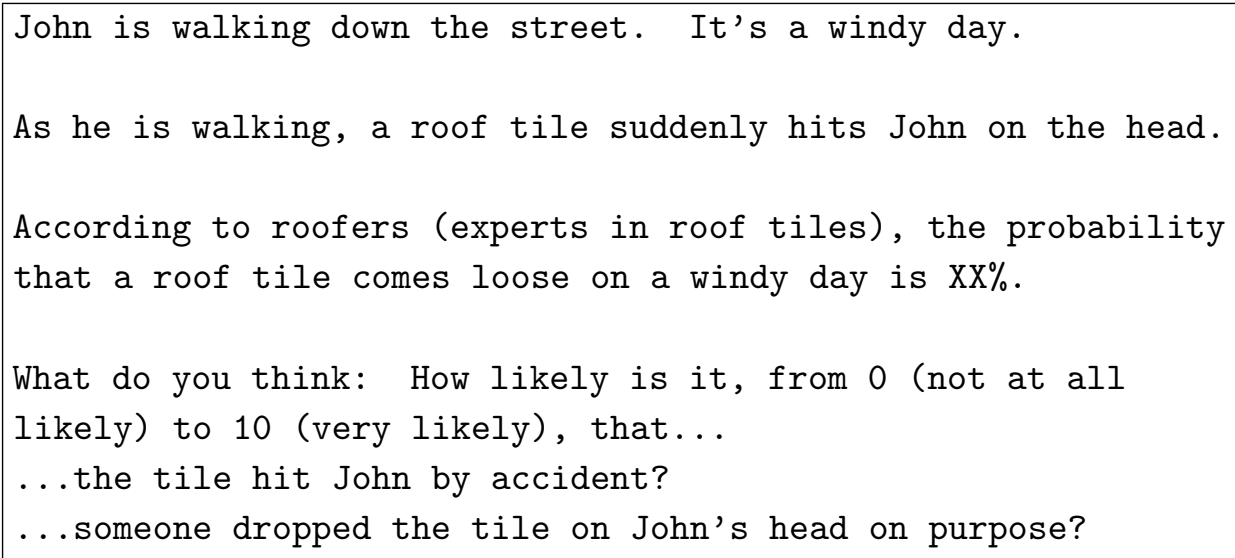

The order of the two questions was randomized. In the text for the first group, the probability of a roof tile coming loose was presented to be $1 \%$. In the second group, that probability was $25 \%$; in the third group, it was $50 \%$; in the fourth group, it was $75 \%$; in the fifth group, it was $99 \%$. As in experiment 
one, participants in both groups were asked to provide information on their gender, their age, and their country of residence upon answering the two questions about the common and the conspiratorial explanation. For the sake of simplicity, the gender options were female and male only.

Experiment two is a low-impact scenario (John being hit on the head is not of general concern for society), and the story lacks a clear ulterior motive.

\subsection{Design of experiment three: Falling roof tile (low impact, clear ulterior motive)}

For experiment three, 504 participants $(61 \%$ women, mean age $=33.4, \mathrm{SD}=$ 12.2) were randomly assigned to five groups: 101 participants were assigned to the first group, 91 to the second group, 103 to the third group, 108 to the fourth group, and 101 to the fifth group. As in experiment two, participants in all groups were exposed to a nearly identical text. The only difference, marked here as $\mathrm{XX} \%$, was the probabilistic information that each group received about the event in question:

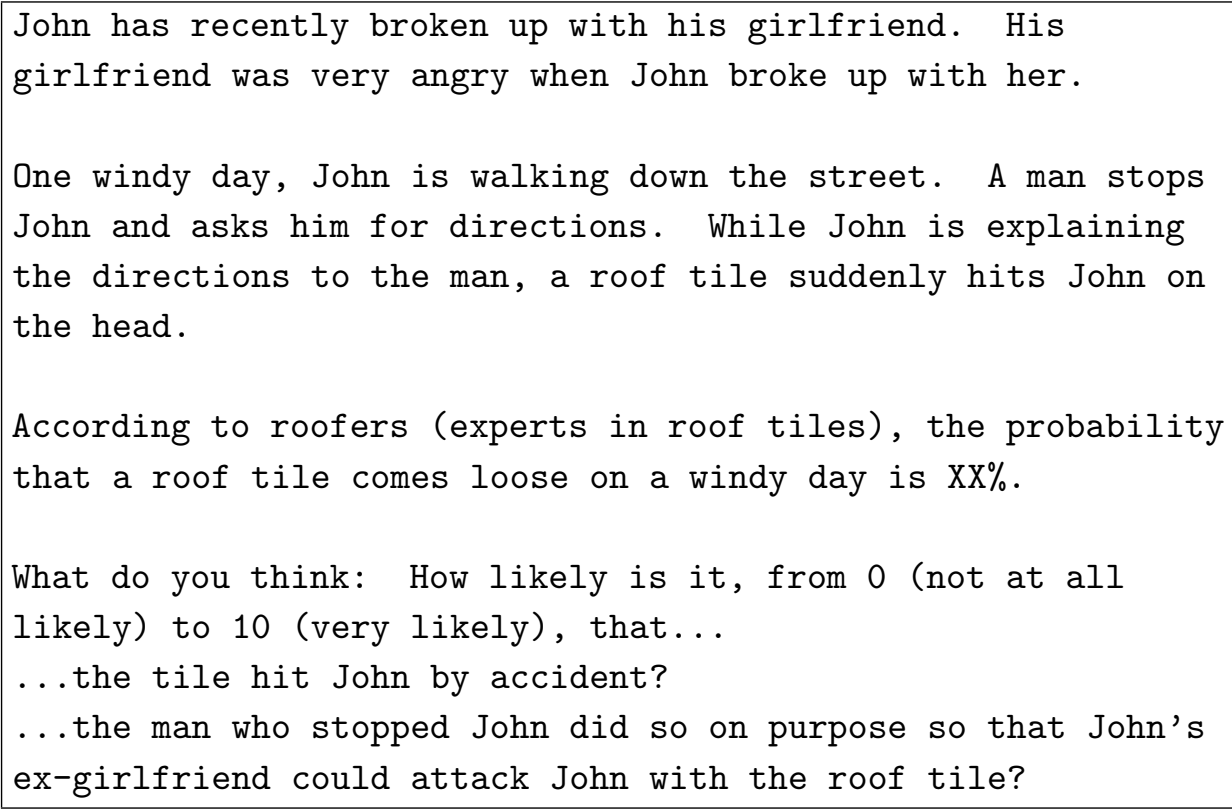

The order of the two questions was randomized. The probabilistic information for the five groups is the same as in experiment two. As in experiments 
one and two, participants in both groups were asked to provide information on their gender, their age, and their country of residence upon answering the two questions about the common and the conspiratorial explanation. For the sake of simplicity, the gender options were female and male only.

Experiment three is a low-impact scenario (John being hit on the head is not of general concern for society), just as experiment two. However, experiment three contains a clear ulterior motive.

\subsection{Design of experiment four: Deceased journalist (high impact, lack of clear ulterior motive)}

For experiment four, 504 participants $(63 \%$ women, mean age $=33.4, \mathrm{SD}=$ 12.0) were randomly assigned to five different groups: 90 participants were assigned to the first group, 105 to the second group, 90 to the third group, 96 to the fourth group, and 123 to the fifth group. Much as in experiments two and three, the participants in all groups of experiment three were exposed to a nearly identical text. The only difference, marked as $\mathrm{XX} \%$, was the probabilistic information that each group received:

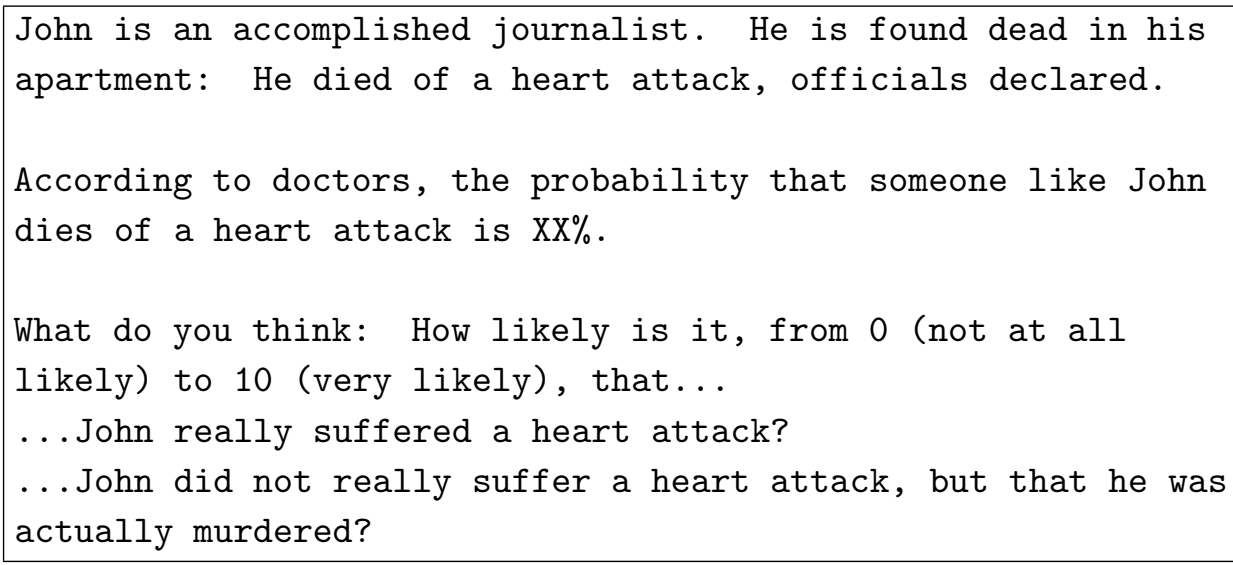

The order of the two questions was randomized. In the text for the first group, the probability of "someone like John" to die of a heart attack was presented to be $1 \%$. The second group, that probability was $25 \%$; in the third group, it was 50\%; in the fourth group, it was $75 \%$; in the fifth group, it was $99 \%$. As in experiments one, two, and three, participants in both groups were asked to provide information on their gender, their age, and their country 
of residence upon answering the two questions about the common and the conspiratorial explanation. For the sake of simplicity, the gender options were female and male only.

Experiment four is a scenario with a high-impact story, the death and potential murder of a journalist, but there is no clear ulterior motive provided in the story.

\subsection{Design of experiment five: Deceased journalist (high impact, clear ulterior motive)}

For experiment five, 502 participants $(64 \%$ women, mean age $=34.0, \mathrm{SD}=$ 12.1) were randomly assigned to five different groups: 103 participants were assigned to the first group, 99 to the second group, 91 to the third group, 124 to the fourth group, and 85 to the fifth group. Once again, the participants in all groups of experiment five were exposed to a nearly identical text. The only difference, marked as XX\%, was the probabilistic information that each group received:

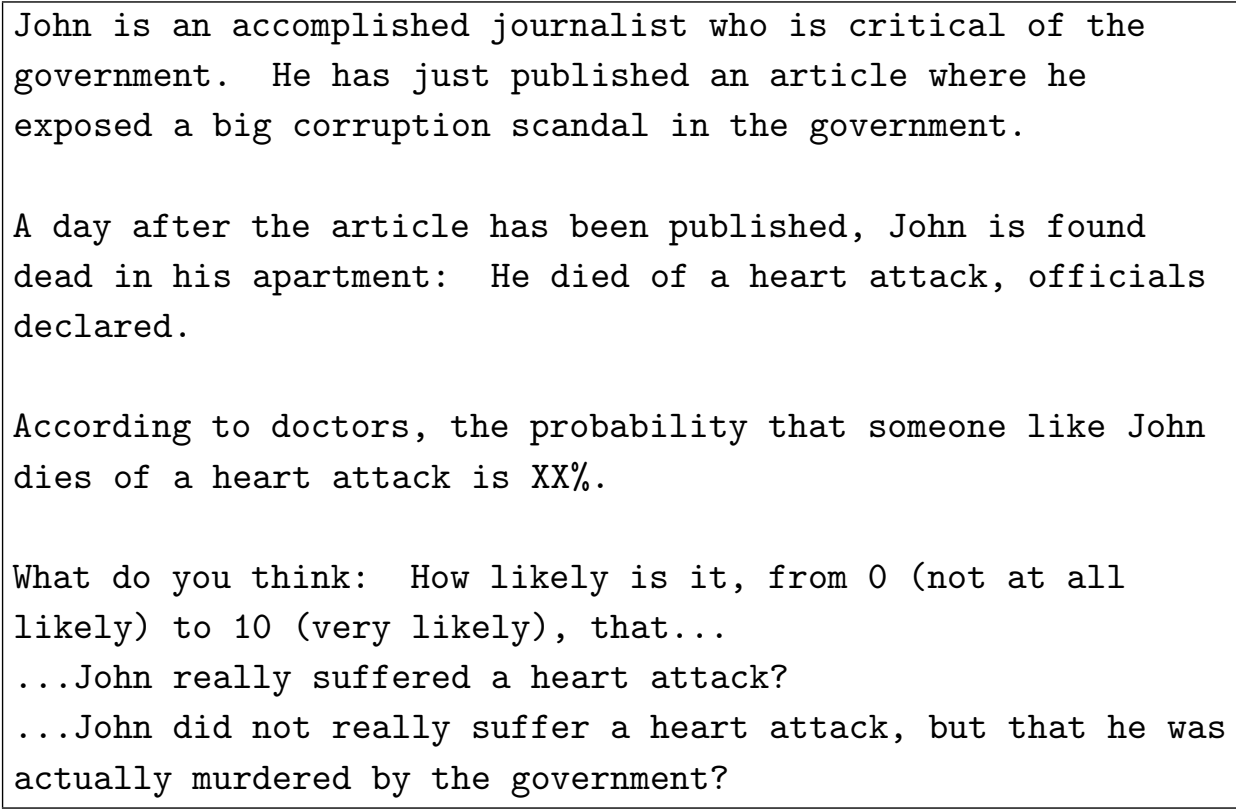

The order of the two questions was randomized. The probabilistic information for the five groups is the same as in experiment four. As in experiments 
one to four, participants in both groups were asked to provide information on their gender, their age, and their country of residence upon answering the two questions about the common and the conspiratorial explanation. For the sake of simplicity, the gender options were female and male only.

Experiment five is a scenario with a high-impact story, the death and potential murder of a journalist, in combination with a clear motive, the government silencing a prominent critic.

\subsection{Data analysis and researcher degrees of freedom}

In any empirical scientific context, so-called researcher degrees of freedom (Simmons, Nelson, \& Simonsohn, 2011) are a challenge. Researcher degrees of freedom describe the fact that between the start of the data collection and the reporting of results, researchers can make and have to make many decisions that determine the final reported results. Unfortunately, many of those decisions are not made a priori, but rather during and after the collection of the data. The general problem with researcher degrees of freedom is that researchers have intrinsic and extrinsic incentives to engage in so-called data dredging (Smith \& Ebrahim, 2002) and p-hacking (Head, Holman, Lanfear, Kahn, \& Jennions, 2015), and even in HARKing (Kerr, 1998) (hypothesizing after the results are known). p-hacking and HARKing are (at the very least) borderline unethical, but the problem of research degrees of freedom is present event when researchers don't actively and knowingly engage in practices such as p-hacking (Gelman \& Loken, 2013).

In our analysis, we have actively sought to minimize researcher degrees of freedom and, where degrees of freedom are present, to make rational decisions. Researcher degrees of freedom in our three experiments pertain to three dimensions: Experiment design, data preparation, and data analysis.

In terms of experiment design, we have made the conscious decision to limit the data collected in the three experiment to precisely the data that is reported: The answers to the two main questions, and, in addition, information on participants' gender, age, and country of residence. We did not collect any additional data - the studies reported here are not, for example, only one part of a larger data set that will be used for additional publications.

In terms of data preparation, we have included all completed surveys into our data analyses. We did not exclude any cases.

In terms of data analysis, we have made two decisions. First, we are only looking at what is sometimes referred to as "main effects": We did 
not estimate any form of interaction effects, and we did not partition data into gender, age, or any other kind of sub-groups. We are simply estimating the data in its most direct form, because that is what we are interested in given our hypothesis. Furthermore, rather than engage in frequentist "significance testing", we are estimating means with the help of Bayesian estimation. Epistemologically, Bayesian estimation is attractive because it is a quantification of uncertainty that does not rely on a test statistic. The models we estimate are all of the following form:

$$
\begin{gathered}
y \sim t(\mu, \sigma, \nu) \\
\mu \sim \mathcal{N}(5,5) \\
\sigma \sim \operatorname{Cauchy}(0,2) \\
\nu \sim \operatorname{Gamma}(2,0.1)
\end{gathered}
$$

The models are estimated using the probabilistic modeling environment Stan (Carpenter et al., 2017) from within the statistical environment $R$ ( R Core Team, 2017). The modeling approach we use is a generalized version of a "robust" estimation of means whereby the Student's $t$ distribution is used as the sampling distribution (Kruschke, 2013; Lange, Little, \& Taylor, 1989). The models were estimated by running 4000 warmup and 4000 sampling iterations with three chains. The estimates converged well, as indicated by potential scale reduction factors (Gelman \& Rubin, 1992) of $\hat{R}=1$.

The model contains three parameters that are specified with priors; these priors represent researcher degrees of freedom. We have specified the prior for the mean $\mu$ as a normal distribution with mean 5 and standard deviation 5. Given the scale of the data $y(0-10)$, the prior for $\mu$ is a rather simple very broad prior. The second parameter in the model, $\sigma$, is modeled as a half-Cauchy distribution (a Cauchy distribution truncated at 0) with scale 2. The half-Cauchy prior is a vaguely informative prior recommended for variance parameters (Polson \& Scott, 2012). Finally, the normality parameter $\nu$ that governs the heaviness of the tails in the $t$ distribution is modeled as a Gamma distribution with shape 2 and scale 0.1 , which represents a vaguely informative prior (Juárez \& Steel, 2010). The Bayesian modeling approach, then, does introduce additional researcher degrees of freedom, but since we are using the same specifications for all models, this means that we are not, for example, arbitrarily changing priors in order to create results that fit our hypothesis. Furthermore, we are consistently using vague priors, meaning 
that the data has much greater say than the likelihood. A practical benefit of the Bayesian approach is that it eliminates incentives for $p$-hacking: There are no $p$-values, and, therefore, there are no "significant" or "not significant" results in the sense of rules of thumb such as $p<0.05$ equals "statistically significant".

We have sought to minimize researcher degrees of freedom and to make rational decisions in those degrees of freedom that are present in our data analysis. In addition, all of our raw, unaltered data will be made available via the Open Science Framework.

\section{Results}

\subsection{Experiment one: The lottery}

The estimation results for experiment one are summarized in Figure 1.

Figure 1: Estimated means for the responses in the two groups (conditions) of experiment one. The estimates for the common explanation are red, and the estimates for the conspiratorial explanation are blue.

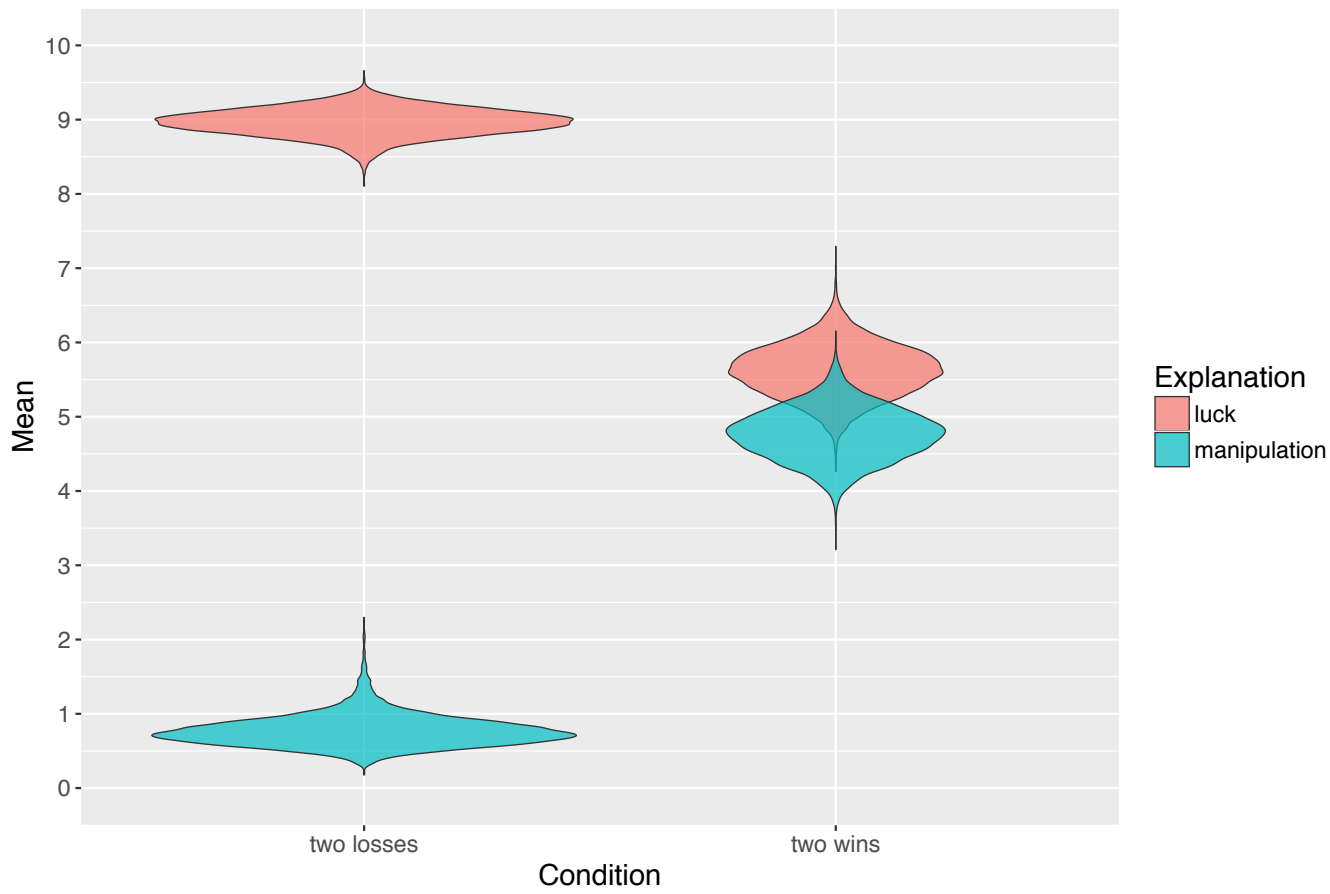


The violin plots in Figure 1 are visualizations of the posterior distribution of the estimated means for the two questions in each group. As can be plainly seen from Figure 1, the estimated means for the two groups are very different. The group that was exposed to the story about John losing twice very strongly believes in the common explanation (luck), and only very weakly in the conspiratorial explanation (manipulation). The situation is quite different in the group that read about John winning twice: The estimated means are very close to each other. The belief in the conspiratorial explanation (manipulation) is much stronger than is the case in the first group; so much so that there is no overlap between the posterior distribution for the conspiratorial explanation (manipulation) between the groups. This means that the true mean is almost certainly lower in the first, (relatively) high probability group (John losing twice) than in the second, low probability group (John winning twice). The same is true for the means of the common explanation (luck): The posterior distributions of the means of the two groups do not overlap, and, therefore, the real mean is almost certainly higher in the first group than in the second group.

The parameter estimates for experiment one are summarized in tabular form in Table 1.

Table 1: Summary of the parameter estimates of experiment one.

\begin{tabular}{lllllll}
\hline Parameter & Condition & Explanation & mean & $2.5 \%$ & $97.5 \%$ & $\hat{R}$ \\
\hline$\mu$ & two losses & common & 8.96 & 8.58 & 9.3 & 1 \\
$\sigma$ & two losses & common & 1.27 & 0.96 & 1.66 & 1 \\
$\nu$ & two losses & common & 1.97 & 1.25 & 3.17 & 1 \\
\hline$\mu$ & two losses & conspiratorial & 0.77 & 0.44 & 1.29 & 1 \\
$\sigma$ & two losses & conspiratorial & 1.15 & 0.79 & 1.77 & 1 \\
$\nu$ & two losses & conspiratorial & 1.62 & 1.05 & 3.09 & 1 \\
\hline$\mu$ & two wins & common & 5.62 & 4.94 & 6.31 & 1 \\
$\sigma$ & two wins & common & 3.69 & 3.25 & 4.2 & 1 \\
$\nu$ & two wins & common & 34.95 & 12.81 & 73.81 & 1 \\
\hline$\mu$ & two wins & conspiratorial & 4.77 & 4.1 & 5.43 & 1 \\
$\sigma$ & two wins & conspiratorial & 3.64 & 3.21 & 4.15 & 1 \\
$\nu$ & two wins & conspiratorial & 35.22 & 12.9 & 73.86 & 1 \\
\hline
\end{tabular}




\subsection{Experiment two: Falling roof tile (low impact, lack of clear ulterior motive)}

The results of the estimates for experiment two are summarized in Figure 2.

Figure 2: Estimated means for the responses in the five groups (conditions) of experiment two. The estimates for the common explanation are red, and the estimates for the conspiratorial explanation are blue.

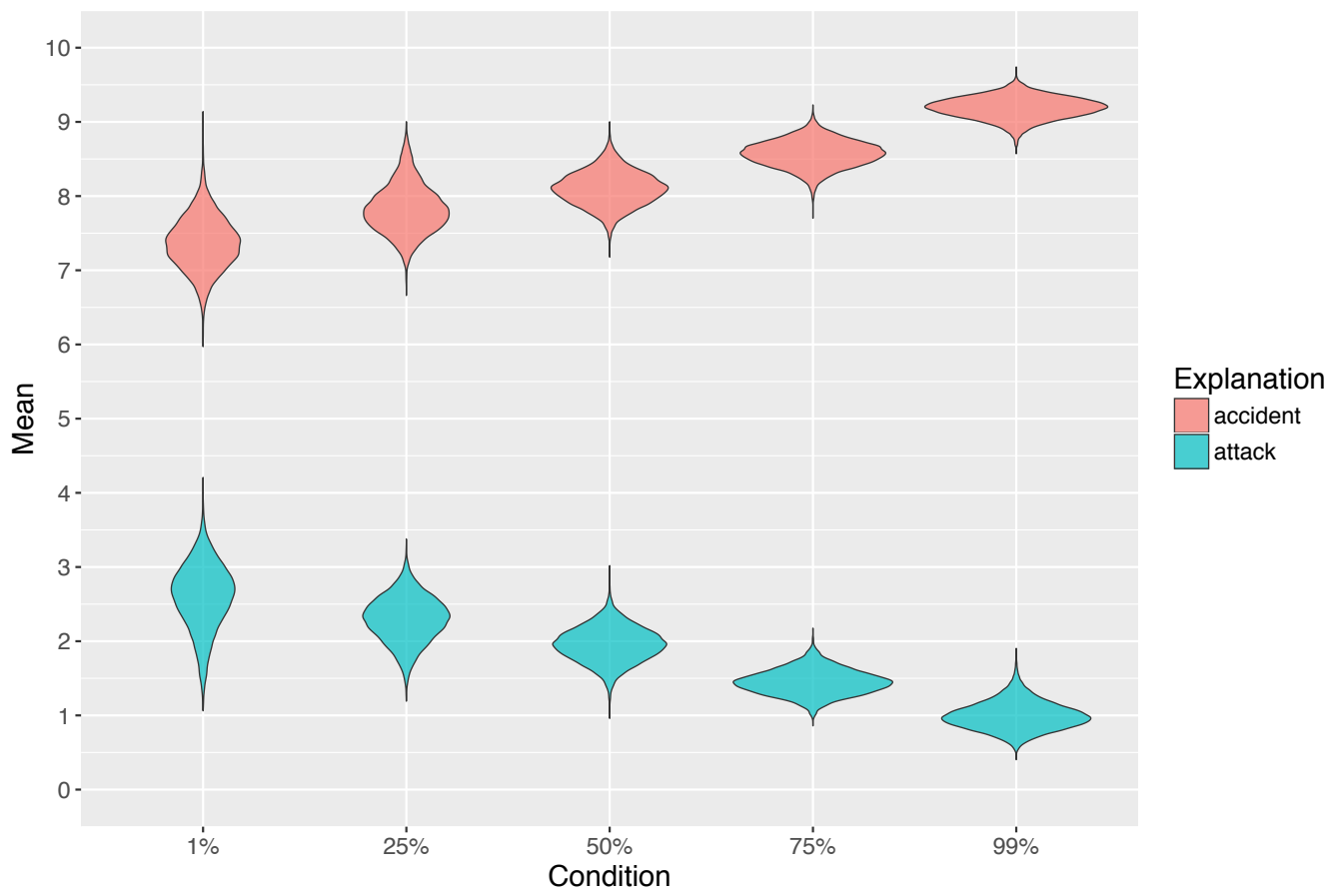

The participants in all five groups clearly believe that the common explanation is much more probable than the conspiratorial one. However, the trend of the means for both explanations is one consistent with our hypothesis: The lower the alleged probability of the event, the higher, on average, the belief in the conspiratorial explanation (attack), and the lower the belief in the common explanation (accident). There is some overlap of the distributions of the $1 \%$ and of the $99 \%$ groups for both questions. This means that it is possible that the true trend of the means between the very low probability and the very high probability group is, in fact, flat or even opposite from what it appears to be visually. Since the distributions in Figure 2 are empirical in nature, we can quantify that probability. The probability that the means 
of the $1 \%$ and $99 \%$ groups for the common explanation (accident) lie within the band of overlapping areas is 0.18 , and the probability that the trend of the two means, were they to lie in that band of overlapping areas, is either flat or negative is 0.09 . Similarly, the probability that the means of the $1 \%$ and $99 \%$ groups for the conspiratorial explanation (attack) lie within the band of overlapping areas is 0.20 , and the probability that the trend of the two means, were they to lie in within the band of overlapping areas, is either flat or negative is 0.03 . Overall, then, the probability that the trends of the means between the very low probability and the very high probability group actually behave as hypothesized is high.

The parameter estimates for the common explanation in experiment two are summarized in tabular form in Table 2.

Table 2: Summary of the parameter estimates for the common explanation in experiment two.

\begin{tabular}{lllllll}
\hline Parameter & Condition & Explanation & mean & $2.5 \%$ & $97.5 \%$ & $\hat{R}$ \\
\hline$\mu$ & $1 \%$ & common & 7.37 & 6.67 & 8.08 & 1 \\
$\sigma$ & $1 \%$ & common & 2.78 & 2.24 & 3.33 & 1 \\
$\nu$ & $1 \%$ & common & 22.52 & 4.43 & 58.35 & 1 \\
\hline$\mu$ & $25 \%$ & common & 7.83 & 7.25 & 8.55 & 1 \\
$\sigma$ & $25 \%$ & common & 2.3 & 1.51 & 2.79 & 1 \\
$\nu$ & $25 \%$ & common & 18.47 & 2.2 & 53.79 & 1 \\
\hline$\mu$ & $50 \%$ & common & 8.1 & 7.66 & 8.56 & 1 \\
$\sigma$ & $50 \%$ & common & 1.94 & 1.57 & 2.31 & 1 \\
$\nu$ & $50 \%$ & common & 17.63 & 4.02 & 49.07 & 1 \\
\hline$\mu$ & $75 \%$ & common & 8.57 & 8.21 & 8.91 & 1 \\
$\sigma$ & $75 \%$ & common & 1.37 & 1.05 & 1.76 & 1 \\
$\nu$ & $75 \%$ & common & 3.98 & 1.91 & 8.95 & 1 \\
\hline$\mu$ & $99 \%$ & common & 9.19 & 8.88 & 9.46 & 1 \\
$\sigma$ & $99 \%$ & common & 1 & 0.74 & 1.34 & 1 \\
$\nu$ & $99 \%$ & common & 1.99 & 1.22 & 3.34 & 1 \\
\hline
\end{tabular}

The parameter estimates for the conspiratorial explanation in experiment two are summarized in tabular form in Table 3. 
Table 3: Summary of the parameter estimates for the conspiratorial explanation in experiment two.

\begin{tabular}{lllllll}
\hline Parameter & Condition & Explanation & mean & $2.5 \%$ & $97.5 \%$ & $\hat{R}$ \\
\hline$\mu$ & $1 \%$ & conspiratorial & 2.6 & 1.6 & 3.38 & 1 \\
$\sigma$ & $1 \%$ & conspiratorial & 2.64 & 1.59 & 3.32 & 1 \\
$\nu$ & $1 \%$ & conspiratorial & 17.68 & 1.87 & 53.15 & 1 \\
\hline$\mu$ & $25 \%$ & conspiratorial & 2.29 & 1.67 & 2.87 & 1 \\
$\sigma$ & $25 \%$ & conspiratorial & 2.17 & 1.5 & 2.67 & 1 \\
$\nu$ & $25 \%$ & conspiratorial & 15.09 & 2.34 & 48.88 & 1 \\
\hline$\mu$ & $50 \%$ & conspiratorial & 1.96 & 1.49 & 2.41 & 1 \\
$\sigma$ & $50 \%$ & conspiratorial & 2.01 & 1.62 & 2.39 & 1 \\
$\nu$ & $50 \%$ & conspiratorial & 18.65 & 4.23 & 50.42 & 1 \\
\hline$\mu$ & $75 \%$ & conspiratorial & 1.45 & 1.13 & 1.79 & 1 \\
$\sigma$ & $75 \%$ & conspiratorial & 1.25 & 0.93 & 1.6 & 1 \\
$\nu$ & $75 \%$ & conspiratorial & 3.15 & 1.62 & 6.05 & 1 \\
\hline$\mu$ & $99 \%$ & conspiratorial & 1 & 0.66 & 1.41 & 1 \\
$\sigma$ & $99 \%$ & conspiratorial & 1.19 & 0.83 & 1.64 & 1 \\
$\nu$ & $99 \%$ & conspiratorial & 2.19 & 1.23 & 4.23 & 1 \\
\hline
\end{tabular}

\subsection{Experiment three: Falling roof tile (low impact, clear ulterior motive)}

The results of the estimates for experiment three are summarized in Figure 3.

In comparison with the estimates for experiment two, the participants in experiment three have stronger beliefs in the conspiratorial explanation when presented with lower alleged probabilities. The difference in results between experiments two and three suggests that the presence of a clear ulterior motive has, ex expected, a mediating effect on conspiratorial belief. The overall trend of the estimated between conditions is not as smooth as in experiment two. However, neither the estimated distribution for the common nor for the conspiratorial explanation have any overlap between the $1 \%$ and the 99\% groups, which suggests that the real trend of the means is as predicted between the very low probability and the very high probability groups.

The parameter estimates for the common explanation in experiment three are summarized in tabular form in Table 4.

The parameter estimates for the conspiratorial explanation in experiment three are summarized in tabular form in Table 5. 
Figure 3: Estimated means for the responses in the five groups (conditions) of experiment three. The estimates for the common explanation are red, and the estimates for the conspiratorial explanation are blue.

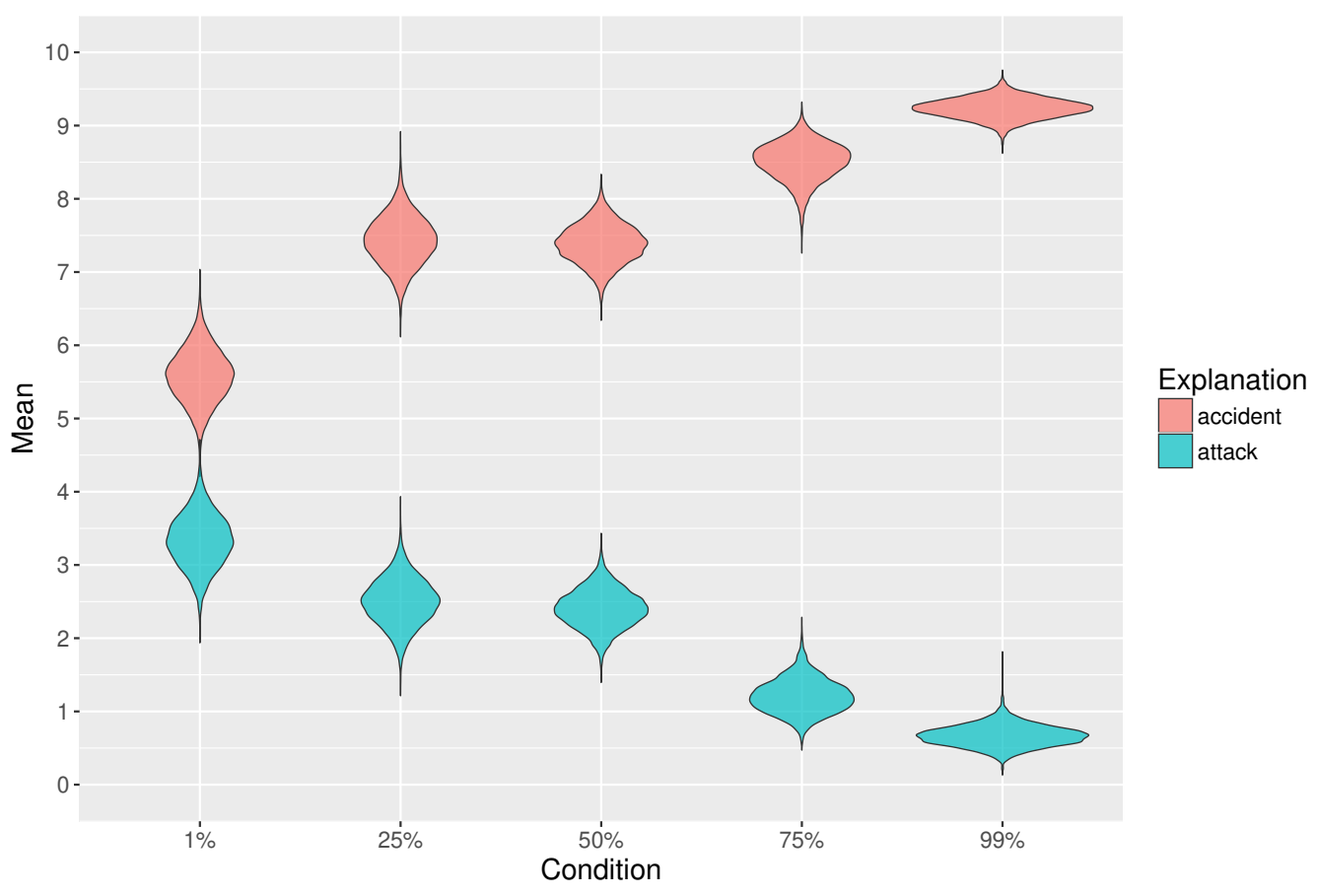

\subsection{Experiment four: Deceased journalist (high im- pact, lack of clear ulterior motive)}

The results of the estimates for experiment four are summarized in Figure 4.

The trends for the estimated means of the belief in the common explanation (heart attack) and for the conspiratorial explanation (murder) in experiment four follow the pattern as predicted by our main hypothesis: The lower the alleged probability of the event, the stronger the belief in a conspiratorial explanation and the weaker the belief in the common explanation. As there is no overlap between the distributions of the $1 \%$ and the $99 \%$ groups, neither for the conspiratorial nor for the common explanation, the true trend between these two means cannot be flat or negative. In comparison to experiments two and three, the belief in the conspiratorial explanation is notably stronger (in the low probability groups). This lends support to the auxiliary hypothesis that a high-impact event increases the endorsment of 
Table 4: Summary of the parameter estimates for the common explanation in experiment three.

\begin{tabular}{lllllll}
\hline Parameter & Condition & Explanation & mean & $2.5 \%$ & $97.5 \%$ & $\hat{R}$ \\
\hline$\mu$ & $1 \%$ & common & 5.59 & 4.88 & 6.31 & 1 \\
$\sigma$ & $1 \%$ & common & 3.53 & 3.06 & 4.06 & 1 \\
$\nu$ & $1 \%$ & common & 33.28 & 11.7 & 72.28 & 1 \\
\hline$\mu$ & $25 \%$ & common & 7.43 & 6.77 & 8.09 & 1 \\
$\sigma$ & $25 \%$ & common & 2.9 & 2.45 & 3.41 & 1 \\
$\nu$ & $25 \%$ & common & 26.53 & 6.81 & 63.49 & 1 \\
\hline$\mu$ & $50 \%$ & common & 7.39 & 6.86 & 7.91 & 1 \\
$\sigma$ & $50 \%$ & common & 2.4 & 2 & 2.83 & 1 \\
$\nu$ & $50 \%$ & common & 21.55 & 5.32 & 54.66 & 1 \\
\hline$\mu$ & $75 \%$ & common & 8.51 & 7.93 & 8.95 & 1 \\
$\sigma$ & $75 \%$ & common & 1.62 & 1.16 & 2.32 & 1 \\
$\nu$ & $75 \%$ & common & 3.44 & 1.5 & 10.47 & 1 \\
\hline$\mu$ & $99 \%$ & common & 9.24 & 8.96 & 9.5 & 1 \\
$\sigma$ & $99 \%$ & common & 0.96 & 0.72 & 1.24 & 1 \\
$\nu$ & $99 \%$ & common & 1.53 & 1.08 & 2.25 & 1 \\
\hline
\end{tabular}

conspiratorial explanations.

The parameter estimates for the common explanation in experiment four are summarized in tabular form in Table 6.

The parameter estimates for the conspiratorial explanation in experiment four are summarized in tabular form in Table 7. 
Table 5: Summary of the parameter estimates for the conspiratorial explanation in experiment three.

\begin{tabular}{lllllll}
\hline Parameter & Condition & Explanation & mean & $2.5 \%$ & $97.5 \%$ & $\hat{R}$ \\
\hline$\mu$ & $1 \%$ & conspiratorial & 3.33 & 2.63 & 4.04 & 1 \\
$\sigma$ & $1 \%$ & conspiratorial & 3.4 & 2.94 & 3.93 & 1 \\
$\nu$ & $1 \%$ & conspiratorial & 31.18 & 9.89 & 69.97 & 1 \\
\hline$\mu$ & $25 \%$ & conspiratorial & 2.5 & 1.86 & 3.12 & 1 \\
$\sigma$ & $25 \%$ & conspiratorial & 2.78 & 2.36 & 3.26 & 1 \\
$\nu$ & $25 \%$ & conspiratorial & 27.19 & 7.58 & 64.17 & 1 \\
\hline$\mu$ & $50 \%$ & conspiratorial & 2.4 & 1.89 & 2.92 & 1 \\
$\sigma$ & $50 \%$ & conspiratorial & 2.45 & 2.06 & 2.85 & 1 \\
$\nu$ & $50 \%$ & conspiratorial & 24.48 & 6.17 & 59.99 & 1 \\
\hline$\mu$ & $75 \%$ & conspiratorial & 1.21 & 0.8 & 1.72 & 1 \\
$\sigma$ & $75 \%$ & conspiratorial & 1.48 & 1.06 & 2.01 & 1 \\
$\nu$ & $75 \%$ & conspiratorial & 4.35 & 1.69 & 14.51 & 1 \\
\hline$\mu$ & $99 \%$ & conspiratorial & 0.67 & 0.4 & 0.97 & 1 \\
$\sigma$ & $99 \%$ & conspiratorial & 0.95 & 0.7 & 1.3 & 1 \\
$\nu$ & $99 \%$ & conspiratorial & 1.38 & 1.02 & 2.04 & 1 \\
\hline
\end{tabular}

\subsection{Experiment five: Deceased journalist (high impact, clear ulterior motive)}

The results of the estimates for experiment three are summarized in Figure 5.

The overall trend of the estimated means once again follows the predicted pattern: The lower the alleged probability of the event, the stronger the belief in the conspiratorial and the weaker the belief in the common explanation. The estimated means of the $1 \%$ and the $99 \%$ groups partly overlap. While there is no overlap for the common explanation, there is some overlap for the conspiratorial explanation. The probability that the means lie in this band of area overlap is 0.19 , and the probability that the trend of the means, were they to actually lie in that band of area overlap, is flat or positive is 0.01 . It is therefore highly probable that the real trend of the means is negative. In comparison with the estimation results for experiment four, the overall belief in the conspiratorial explanation is much stronger. This lends further support to the auxiliary hypothesis that a clear ulterior motive increases the endorsement of conspiratorial beliefs. Within experiments two to five, the levels of conspiratorial belief are strongest in experiment five. This suggests that, as expected, conspiratorial beliefs are strongest in a high-impact, clear 
Figure 4: Estimated means for the responses in the five groups (conditions) of experiment four. The estimates for the common explanation are red, and the estimates for the conspiratorial explanation are blue.

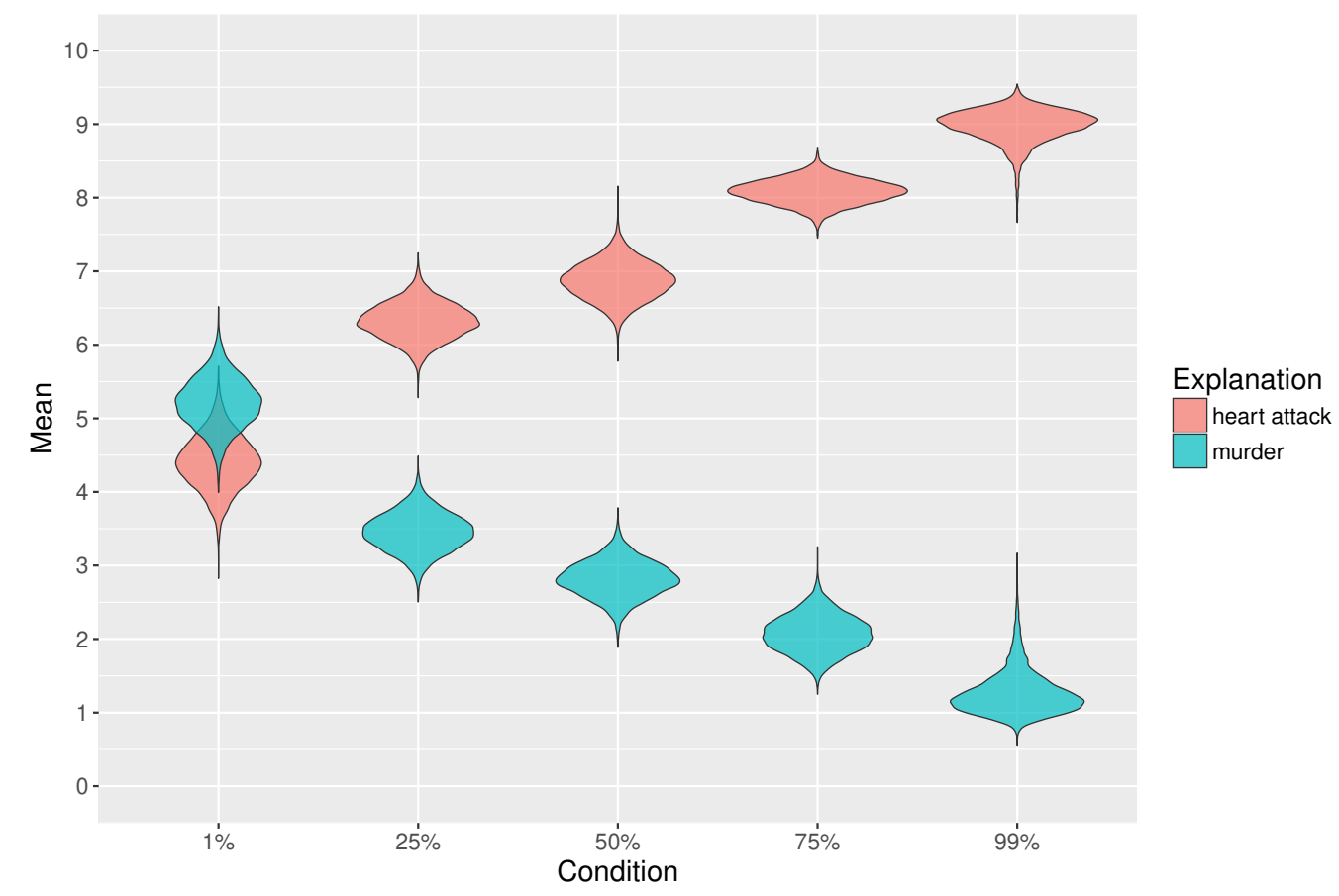

ulterior motive scenario.

The parameter estimates for the common explanation in experiment five are summarized in tabular form in Table 8.

The parameter estimates for the conspiratorial explanation in experiment five are summarized in tabular form in Table 9. 
Table 6: Summary of the parameter estimates for the common explanation in experiment four.

\begin{tabular}{lllllll}
\hline & condition & explanation & mean & $2.5 \%$ & $97.5 \%$ & $\hat{R}$ \\
\hline$\mu$ & $1 \%$ & common & 4.4 & 3.69 & 5.13 & 1 \\
$\sigma$ & $1 \%$ & common & 3.25 & 2.8 & 3.79 & 1 \\
$\nu$ & $1 \%$ & common & 30.87 & 9.92 & 68.22 & 1 \\
\hline$\mu$ & $25 \%$ & common & 6.32 & 5.84 & 6.8 & 1 \\
$\sigma$ & $25 \%$ & common & 2.38 & 2.05 & 2.75 & 1 \\
$\nu$ & $25 \%$ & common & 28.02 & 8.51 & 65.07 & 1 \\
\hline$\mu$ & $50 \%$ & common & 6.87 & 6.37 & 7.38 & 1 \\
$\sigma$ & $50 \%$ & common & 2.28 & 1.94 & 2.69 & 1 \\
$\nu$ & $50 \%$ & common & 24.29 & 6.62 & 59.59 & 1 \\
\hline$\mu$ & $75 \%$ & common & 8.08 & 7.76 & 8.4 & 1 \\
$\sigma$ & $75 \%$ & common & 1.47 & 1.21 & 1.75 & 1 \\
$\nu$ & $75 \%$ & common & 18.65 & 4.55 & 51.09 & 1 \\
\hline$\mu$ & $99 \%$ & common & 8.98 & 8.45 & 9.32 & 1 \\
$\sigma$ & $99 \%$ & common & 1.24 & 0.85 & 1.89 & 1 \\
$\nu$ & $99 \%$ & common & 1.92 & 1.09 & 4.19 & 1 \\
\hline
\end{tabular}

Table 7: Summary of the parameter estimates for the conspiratorial explanation in experiment four.

\begin{tabular}{lllllll}
\hline & condition & explanation & mean & $2.5 \%$ & $97.5 \%$ & $\hat{R}$ \\
\hline$\mu$ & $1 \%$ & conspiratorial & 5.21 & 4.53 & 5.9 & 1 \\
$\sigma$ & $1 \%$ & conspiratorial & 3.11 & 2.68 & 3.62 & 1 \\
$\nu$ & $1 \%$ & conspiratorial & 30.34 & 9.84 & 68.09 & 1 \\
\hline$\mu$ & $25 \%$ & conspiratorial & 3.46 & 2.94 & 3.97 & 1 \\
$\sigma$ & $25 \%$ & conspiratorial & 2.57 & 2.23 & 2.96 & 1 \\
$\nu$ & $25 \%$ & conspiratorial & 27.93 & 8.7 & 64.55 & 1 \\
\hline$\mu$ & $50 \%$ & conspiratorial & 2.82 & 2.32 & 3.3 & 1 \\
$\sigma$ & $50 \%$ & conspiratorial & 2.2 & 1.88 & 2.58 & 1 \\
$\nu$ & $50 \%$ & conspiratorial & 26.63 & 7.7 & 62.38 & 1 \\
\hline$\mu$ & $75 \%$ & conspiratorial & 2.07 & 1.6 & 2.57 & 1 \\
$\sigma$ & $75 \%$ & conspiratorial & 1.78 & 1.28 & 2.26 & 1 \\
$\nu$ & $75 \%$ & conspiratorial & 9.97 & 2.29 & 36.23 & 1 \\
\hline$\mu$ & $99 \%$ & conspiratorial & 1.27 & 0.87 & 2.09 & 1 \\
$\sigma$ & $99 \%$ & conspiratorial & 1.39 & 0.88 & 2.39 & 1 \\
$\nu$ & $99 \%$ & conspiratorial & 2.27 & 1.06 & 7.67 & 1 \\
\hline
\end{tabular}


Figure 5: Estimated means for the responses in the five groups (conditions) of experiment five. The estimates for the common explanation are red, and the estimates for the conspiratorial explanation are blue.

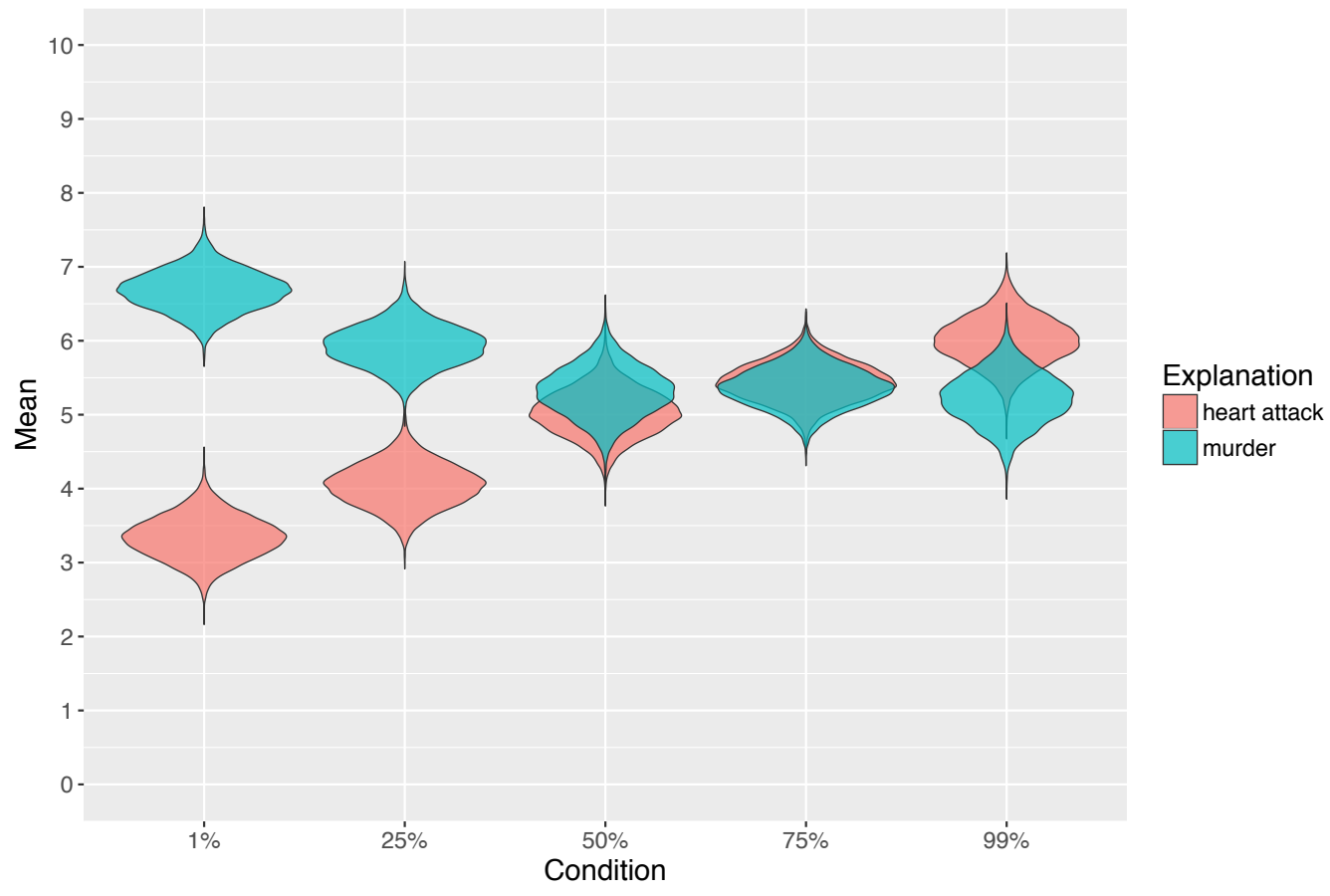


Table 8: Summary of the parameter estimates for the common explanation in experiment five.

\begin{tabular}{lllllll}
\hline & condition & explanation & mean & $2.5 \%$ & $97.5 \%$ & $\hat{R}$ \\
\hline$\mu$ & $1 \%$ & common & 3.34 & 2.79 & 3.91 & 1 \\
$\sigma$ & $1 \%$ & common & 2.74 & 2.35 & 3.19 & 1 \\
$\nu$ & $1 \%$ & common & 26.99 & 7.73 & 62.75 & 1 \\
\hline$\mu$ & $25 \%$ & common & 4.05 & 3.48 & 4.63 & 1 \\
$\sigma$ & $25 \%$ & common & 2.79 & 2.4 & 3.24 & 1 \\
$\nu$ & $25 \%$ & common & 29.19 & 8.85 & 66.15 & 1 \\
\hline$\mu$ & $50 \%$ & common & 5.02 & 4.4 & 5.65 & 1 \\
$\sigma$ & $50 \%$ & common & 2.87 & 2.46 & 3.36 & 1 \\
$\nu$ & $50 \%$ & common & 28.62 & 8.58 & 66 & 1 \\
\hline$\mu$ & $75 \%$ & common & 5.45 & 4.93 & 5.96 & 1 \\
$\sigma$ & $75 \%$ & common & 2.79 & 2.43 & 3.19 & 1 \\
$\nu$ & $75 \%$ & common & 31.21 & 10.06 & 70.36 & 1 \\
\hline$\mu$ & $99 \%$ & common & 6 & 5.36 & 6.64 & 1 \\
$\sigma$ & $99 \%$ & common & 2.83 & 2.41 & 3.34 & 1 \\
$\nu$ & $99 \%$ & common & 28.03 & 7.97 & 65.05 & 1 \\
\hline
\end{tabular}

Table 9: Summary of the parameter estimates for the conspiratorial explanation in experiment five.

\begin{tabular}{lllllll}
\hline & condition & explanation & mean & $2.5 \%$ & $97.5 \%$ & $\hat{R}$ \\
\hline$\mu$ & $1 \%$ & conspiratorial & 6.68 & 6.15 & 7.23 & 1 \\
$\sigma$ & $1 \%$ & conspiratorial & 2.61 & 2.23 & 3.04 & 1 \\
$\nu$ & $1 \%$ & conspiratorial & 26.26 & 7.32 & 62.6 & 1 \\
\hline$\mu$ & $25 \%$ & conspiratorial & 5.93 & 5.38 & 6.48 & 1 \\
$\sigma$ & $25 \%$ & conspiratorial & 2.69 & 2.31 & 3.13 & 1 \\
$\nu$ & $25 \%$ & conspiratorial & 28.82 & 8.87 & 64.64 & 1 \\
\hline$\mu$ & $50 \%$ & conspiratorial & 5.32 & 4.65 & 5.98 & 1 \\
$\sigma$ & $50 \%$ & conspiratorial & 3.06 & 2.63 & 3.58 & 1 \\
$\nu$ & $50 \%$ & conspiratorial & 30.14 & 9.6 & 67.13 & 1 \\
\hline$\mu$ & $75 \%$ & conspiratorial & 5.36 & 4.82 & 5.89 & 1 \\
$\sigma$ & $75 \%$ & conspiratorial & 2.87 & 2.52 & 3.27 & 1 \\
$\nu$ & $75 \%$ & conspiratorial & 32.41 & 11.22 & 69.32 & 1 \\
\hline$\mu$ & $99 \%$ & conspiratorial & 4.54 & 5.89 & 5.89 & 1 \\
$\sigma$ & $99 \%$ & conspiratorial & 2.62 & 3.6 & 3.6 & 1 \\
$\nu$ & $99 \%$ & conspiratorial & 9.74 & 67.4 & 67.4 & 1 \\
\hline
\end{tabular}




\section{Discussion}

\subsection{Limitations of this study}

Besides the general limitations of any singular study (the main hypothesis needs to be further explored and the experiments replicated), we suspect that the framing of our experiments biased participants' responses. More specifically, we have presented the alleged probabilities for events as $\operatorname{Pr}($ event $\mid$ chance $)$. The participants were asked to estimate $\operatorname{Pr}($ chance | event $)$ and $\operatorname{Pr}($ conspiracy | event). It is possible that some or even all participants have simply interpreted $\operatorname{Pr}($ event $\mid$ chance $)$ as $\operatorname{Pr}($ chance | event $)$ and $\operatorname{Pr}($ conspiracy $\mid$ event $)$ as $1-\operatorname{Pr}($ event $\mid$ chance $)$. Even though both of those deductions are incorrect, the framing of the experiments might have nudged the participants towards such an interpretation. Future research on the relationship between probability and conspiratorial thinking should therefore be designed in a way that avoids this potential bias.

\subsection{Conspiratorial thinking as a possible cognitive heuris- tic}

Overall, the five experiments lend support to the hypothesis we set out to test: The lower the probability of an event, the stronger the belief in a conspiratorial explanation, and the weaker the belief in the common explanation. In addition, the results suggest that high-impact scenarios as well as scenarios with clear ulterior motives induce stronger belief in conspiratorial explanations. These results are not all that surprising in light of what is known about how humans handle probabilities: A number of cognitive biases are, in essence, errors in probabilistic thinking, and conspiratorial reasoning might represent just another such bias. For example, we know that humans tend to have a difficult time with handling low probability events, especially if the events in question have both low probability and high impact; this trait is sometimes described with the black swan metaphor (Taleb, 2010; Wardman \& Mythen, 2016). In this context, conspiratorial thinking as a potential cognitive bias might represent a general strategy for handling probabilistic information, or, expressed more generally, a coping strategy for uncertainty, since probability is a quantification of uncertainty.

If conspiratorial thinking occurs as a general cognitive bias and not only as a pathology of the mind, that means that it might also be possible to devise 
countermeasures against conspiratorial thinking that have an effect of generalized debiasing (Croskerry, Singhal, \& Mamede, 2013; Lilienfeld, Ammirati, \& Landfield, 2009). In order to tackle specific singular conspiracy theories, "debunking" them might work. In order to tackle conspiratorial thinking in general, metacognitive debiasing as a form of training in probabilistic thinking might be more effective. 


\section{References}

Barron, D., Morgan, K., Towell, T., Altemeyer, B., \& Swami, V. (2014, November). Associations between schizotypy and belief in conspiracist ideation. Personality and Individual Differences, 70, 156-159. Retrieved 2017-03-19, from http://www.sciencedirect.com/science/ article/pii/S0191886914003821 doi: 10.1016/j.paid.2014.06.040

Basham, L. (2001, January). Living with the Conspiracy. The Philosophical Forum, 32(3), 265-280. Retrieved 201703-02, from http://onlinelibrary.wiley.com/doi/10.1111/0031 -806X.00065/abstract doi: 10.1111/0031-806X.00065

Bentall, R. P., Kinderman, P., \& Kaney, S. (1994, March). The self, attributional processes and abnormal beliefs: Towards a model of persecutory delusions. Behaviour Research and Therapy, 32(3), 331-341. Retrieved 2017-03-19, from http://www.sciencedirect.com/science/ article/pii/0005796794901317 doi: 10.1016/0005-7967(94)90131-7

Boudry, M., \& Braeckman, J. (2012, June). How convenient! The epistemic rationale of self-validating belief systems. Philosophical Psychology, 25(3), 341-364. Retrieved 2017-03-19, from http://dx.doi.org/10 .1080/09515089.2011.579420 doi: 10.1080/09515089.2011.579420

Brotherton, R., \& French, C. C. (2014). Belief in Conspiracy Theories and Susceptibility to the Conjunction Fallacy. Applied Cognitive Psychology, 28(2), 238-248. Retrieved 2017-03-16, from http:// onlinelibrary.wiley.com/doi/10.1002/acp.2995/abstract doi: 10.1002/acp. 2995

Carpenter, B., Gelman, A., Hoffman, M., Lee, D., Goodrich, B., Betancourt, M., .. Riddell, A. (2017). Stan: A Probabilistic Programming Language. Journal of Statistical Software, 76(1), 1-32. Retrieved from https://www.jstatsoft.org/index.php/jss/article/ view/v076i01 (bibtex: JSSv076i01) doi: 10.18637/jss.v076.i01

Clarke, S. (2002, June). Conspiracy Theories and Conspiracy Theorizing. Philosophy of the Social Sciences, 32(2), 131-150. Retrieved 2016-0913, from http://pos.sagepub.com/content/32/2/131 doi: 10.1177/ 004931032002001

Croskerry, P., Singhal, G., \& Mamede, S. (2013, October). Cognitive debiasing 1: origins of bias and theory of debiasing. BMJ Quality 8 Safety, 22(Suppl 2), ii58-ii64. Retrieved 2016-12-05, from http://

qualitysafety.bmj.com/content/22/Suppl_2/ii58 doi: 10.1136/ 
bmjqs-2012-001712

Dagnall, N., Denovan, A., Drinkwater, K., Parker, A., \& Clough, P. (2017, July). Statistical Bias and Endorsement of Conspiracy Theories. Applied Cognitive Psychology, 31(4), 368-378. Retrieved 2017-07-22, from http://onlinelibrary.wiley.com/doi/10.1002/ acp.3331/abstract doi: 10.1002/acp.3331

Darwin, H., Neave, N., \& Holmes, J. (2011, June). Belief in conspiracy theories. The role of paranormal belief, paranoid ideation and schizotypy. Personality and Individual Differences, 50(8), 1289-1293. Retrieved 2017-03-19, from http://www.sciencedirect.com/science/ article/pii/S0191886911001036 doi: 10.1016/j.paid.2011.02.027

Douglas, K., Sutton, R. M., Jolley, D., \& Wood, M. J. (2015, June). The social, political, environmental and health-related consequences of conspiracy theories: Problems and potential solutions. In M. Bilewicz, A. Cichocka, \& W. Soral (Eds.), The psychology of conspiracy. Taylor and Francis. Retrieved 2017-03-23, from https ://kar.kent.ac.uk/48294/

Douglas, K. M., Sutton, R. M., Callan, M. J., Dawtry, R. J., \& Harvey, A. J. (2016, January). Someone is pulling the strings: hypersensitive agency detection and belief in conspiracy theories. Thinking \& Reasoning, 22(1), 57-77. Retrieved 2017-03-16, from http://dx.doi.org/10.1080/ 13546783.2015.1051586 doi: 10.1080/13546783.2015.1051586

Franks, B., Bangerter, A., \& Bauer, M. (2013). Conspiracy theories as quasi-religious mentality: an integrated account from cognitive science, social representations theory, and frame theory. Frontiers in Psychology, 4. Retrieved 2017-03-23, from http://journal.frontiersin.org/ article/10.3389/fpsyg. 2013.00424/abstract doi: 10.3389/fpsyg .2013 .00424

Gelman, A., \& Loken, E. (2013). The garden of forking paths: Why multiple comparisons can be a problem, even when there is no "fishing expedition" or "p-hacking" and the research hypothesis was posited ahead of time. Department of Statistics, Columbia University.

Gelman, A., \& Rubin, D. B. (1992, November). Inference from Iterative Simulation Using Multiple Sequences. Statistical Science, 7(4), 457-472. Retrieved 2016-03-28, from http://projecteuclid.org/euclid.ss/ 1177011136 doi: $10.1214 / \mathrm{ss} / 1177011136$

Gettier, E. L. (1963). Is Justified True Belief Knowledge? Analysis, 23(6), 121-123. Retrieved 2017-03-02, from http://www.jstor.org/stable/ 3326922 doi: 10.2307/3326922 
Head, M. L., Holman, L., Lanfear, R., Kahn, A. T., \& Jennions, M. D. (2015, March). The Extent and Consequences of P-Hacking in Science. PLOS Biology, 13(3), e1002106. Retrieved 2017-0326, from http://journals.plos.org/plosbiology/article?id=10 .1371/journal.pbio.1002106 doi: 10.1371/journal.pbio.1002106

Jolley, D., \& Douglas, K. M. (2014a, February). The Effects of AntiVaccine Conspiracy Theories on Vaccination Intentions. PLOS ONE, 9(2), e89177. Retrieved 2017-03-19, from http://journals.plos .org/plosone/article?id=10.1371/journal.pone.0089177 doi: 10.1371/journal.pone.0089177

Jolley, D., \& Douglas, K. M. (2014b, February). The social consequences of conspiracism: Exposure to conspiracy theories decreases intentions to engage in politics and to reduce one's carbon footprint. British Journal of Psychology, 105(1), 35-56. Retrieved 2017-03-19, from http://onlinelibrary.wiley.com/doi/10.1111/bjop.12018/ abstract doi: 10.1111/bjop.12018

Juárez, M. A., \& Steel, M. F. J. (2010, January). Model-Based Clustering of Non-Gaussian Panel Data Based on Skew-t Distributions. Journal of Business 85 Economic Statistics, 28(1), 52-66. Retrieved 2017-0326, from http://amstat.tandfonline.com/doi/abs/10.1198/jbes .2009.07145 doi: 10.1198/jbes.2009.07145

Keeley, B. L. (1999). Of Conspiracy Theories. The Journal of Philosophy, 96(3), 109-126. Retrieved 2015-02-11, from http://www.jstor.org/ stable/2564659 doi: 10.2307/2564659

Kerr, N. L. (1998, August). HARKing: Hypothesizing After the Results are Known. Personality and Social Psychology Review, 2(3), 196-217. Retrieved 2017-03-26, from http://dx.doi.org/10.1207/ s15327957pspr0203_4 doi: 10.1207/s15327957pspr0203_4

Kruschke, J. K. (2013, May). Bayesian estimation supersedes the t test. Journal of Experimental Psychology. General, 142(2), 573-603. doi: $10.1037 / \mathrm{a} 0029146$

Lange, K., Little, R. J. A., \& Taylor, J. (1989, November). Robust Statistical Modeling Using the t- Distribution. eScholarship. Retrieved 2016-11-08, from http://escholarship.org/uc/item/27s1d3h7

Leman, P. J., \& Cinnirella, M. (2007). A major event has a major cause: Evidence for the role of heuristics in reasoning about conspiracy theories. Soc. Psychol. Rev, 9, 18-28.

Leman, P. J., \& Cinnirella, M. (2013). Beliefs in conspiracy theories and the 
need for cognitive closure. Frontiers in Psychology, 4. Retrieved 201703-16, from http://journal.frontiersin.org/article/10.3389/ fpsyg. 2013.00378/abstract doi: 10.3389/fpsyg.2013.00378

Lilienfeld, S. O., Ammirati, R., \& Landfield, K. (2009, July). Giving Debiasing Away: Can Psychological Research on Correcting Cognitive Errors Promote Human Welfare? Perspectives on Psychological Science, 4 (4), 390-398. Retrieved 2017-10-25, from https://doi.org/10.1111/ j.1745-6924.2009.01144.x doi: 10.1111/j.1745-6924.2009.01144.x

LimeSurvey Project Team / Carsten Schmitz. (2012). LimeSurvey: An Open Source survey tool. Hamburg, Germany: LimeSurvey Project. Retrieved from http: //www. limesurvey.org

Lutz, J. (2015, December). The Validity of Crowdsourcing Data in Studying Anger and Aggressive Behavior. Social Psychology, 47(1), 38-51. Retrieved 2017-03-19, from http://econtent.hogrefe.com/doi/full/ 10.1027/1864-9335/a000256 doi: 10.1027/1864-9335/a000256

Marchlewska, M., Cichocka, A., \& Kossowska, M. (2017). Addicted to answers: Need for cognitive closure and the endorsement of conspiracy beliefs. European Journal of Social Psychology, n/a-n/a. Retrieved 2017-07-22, from http://onlinelibrary.wiley.com/doi/10.1002/ ejsp.2308/abstract doi: 10.1002/ejsp.2308

Oliver, J. E., \& Wood, T. (2014b, May). Medical Conspiracy Theories and Health Behaviors in the United States. JAMA Internal Medicine, 174(5), 817-818. Retrieved 2017-03-19, from http://jamanetwork .com/journals/jamainternalmedicine/fullarticle/1835348 doi: 10.1001/jamainternmed.2014.190

Oliver, J. E., \& Wood, T. J. (2014a). Conspiracy Theories and the Paranoid Style(s) of Mass Opinion. American Journal of Political Science, 58(4), 952-966. Retrieved 2017-03-16, from http://onlinelibrary.wiley .com/doi/10.1111/ajps.12084/abstract doi: 10.1111/ajps.12084

Polson, N. G., \& Scott, J. G. (2012, December). On the Half-Cauchy Prior for a Global Scale Parameter. Bayesian Analysis, 7(4), 887-902. Retrieved 2017-01-01, from http://projecteuclid.org/euclid.ba/ 1354024466 doi: 10.1214/12-BA730

Pritchard, D. (2004, July). Epistemic Luck. Journal of Philosophical Research, 29, 191-220. Retrieved 2017-05-12, from https://www.pdcnet.org/pdc/bvdb.nsf/purchase?openform\&fp= jpr\&id=jpr_2004_0029_0191_0220 doi: 10.5840/jpr_2004_18

R Core Team. (2017). R: A Language and Environment for Statistical 
Computing. Vienna, Austria: R Foundation for Statistical Computing. Retrieved from https://www.R-project.org/

Simmons, J. P., Nelson, L. D., \& Simonsohn, U. (2011, November). FalsePositive Psychology: Undisclosed Flexibility in Data Collection and Analysis Allows Presenting Anything as Significant. Psychological Science, 22(11), 1359-1366. Retrieved 2017-03-26, from http://dx.doi .org/10.1177/0956797611417632 doi: 10.1177/0956797611417632

Smith, G. D., \& Ebrahim, S. (2002, December). Data dredging, bias, or confounding. BMJ : British Medical Journal, 325(7378), 14371438. Retrieved 2017-03-26, from http://www.ncbi.nlm.nih.gov/ pmc/articles/PMC1124898/

Sunstein, C. R., \& Vermeule, A. (2009, June). Conspiracy Theories: Causes and Cures. Journal of Political Philosophy, 17(2), 202-227. Retrieved 2014-08-03, from http://onlinelibrary.wiley.com/doi/10.1111/j .1467-9760.2008.00325.x/abstract doi: 10.1111/j.1467-9760.2008 $.00325 . \mathrm{x}$

Swami, V., Weis, L., Lay, A., Barron, D., \& Furnham, A. (2016, February). Associations between belief in conspiracy theories and the maladaptive personality traits of the personality inventory for DSM-5. Psychiatry Research, 236, 86-90. Retrieved 201703-19, from http://www.sciencedirect.com/science/article/pii/ S016517811530264X doi: 10.1016/j.psychres.2015.12.027

Taleb, N. N. (2010). The Black Swan: The Impact of the Highly Improbable (2edition ed.). New York: Random House Trade Paperbacks.

Tversky, A., \& Kahneman, D. (1974, September). Judgment under Uncertainty: Heuristics and Biases. Science, 185(4157), 1124-1131. Retrieved 2015-02-11, from http://www. sciencemag.org/content/185/ 4157/1124 doi: 10.1126/science.185.4157.1124

Uscinski, J. E., \& Parent, J. M. (2014). American conspiracy theories. Oxford University Press.

van Prooijen, J.-W., \& van Dijk, E. (2014, November). When consequence size predicts belief in conspiracy theories: The moderating role of perspective taking. Journal of Experimental Social Psychology, 55, 63-73. Retrieved 2017-03-19, from http://www. sciencedirect.com/ science/article/pii/S0022103114000948 doi: 10.1016/j.jesp.2014 .06 .006

Wardman, J. K., \& Mythen, G. (2016, November). Risk communication: against the Gods or against all odds? Problems and prospects 
of accounting for Black Swans. Journal of Risk Research, 19(10), 1220-1230. Retrieved 2016-12-26, from http://dx.doi.org/10.1080/ 13669877.2016.1262002 doi: 10.1080/13669877.2016.1262002 